\title{
Model Evaluation of the Impact of Thermally Induced Valley Circulations in the Lake Powell Area on Long- Range Pollutant Transport
}

\author{
M. Segal, C.-H. Yu and R. A. Pielke \\ Department of Atmospheric Science \\ Colorado State University \\ Fort Collins, Colorado
}

\begin{abstract}
A numerical mesoscale model was used to simulate meteorological fields in the Lake Powell area during the summer, providing an input to a Lagrangian-type transport/dispersion model evaluation. The main objective of the study was to use these modeling tools in order to evaluate the local effect of thermally-induced circulations on large-scale transport of polluted air masses into that area. Results indicated a substantial modification of the transport characteristics due to the local terrain-forced circulations. Most noticeable are: (i) trapping of pollutants within the Lake Powell valley, (ii) upward and downward venting of pollutants in convergence/divergence zones associated with these circulations, and (iii) slowing of crossvalley transport as compared to equivalent situations involved with flat terrain.
\end{abstract}

Observations in the Lake Powell area have indicated that a significant visibility impairment often exists in this area located in southern Utah and northern Arizona (a schematic illustration of the area is provided in Figure 1). Since several National Park areas within this region are mandated by federal legislaton as Class I areas under the Prevention of Significant Deterioration (PSD) of the federal air quality program, considerable research effort has been devoted in recent years to understand the atmospheric processes affecting visibility in that area. Studies evaluating the potential contribution of local sources in the area to the visibility impairment is reported, for example, in Bluemental et al., ${ }^{1}$ and $\mathrm{Yu}$ and Pielke. ${ }^{2}$ Most of the focus in recent years, however, has been directed to visibility oriented studies including evaluations of the impact of long-range transport of polluted air masses into the area during the summer. During the summer, a shallow thermal low dominates the lower atmosphere of the southwest United States (e.g., Tang and Rieter ${ }^{3}$ ). Studies reported, for example, by Pitchford, ${ }^{4}$ Macias, ${ }^{5}$ Flucihini et al., ${ }^{6}$ Ashbaugh et al. ${ }^{7}$ suggest that southwest synoptic flow associated with that meteorological system may lead to the long-range transport of polluted air masses from southern California and southern Arizona into the
Lake Powell area. Also, these studies suggested situations involved with southeast synoptic flow advecting polluted air into the Lake Powell area from New Mexico and Texas. This second common transport situation is associated with flow around the west side of a subtropical ridge which is situated to the east of the thermal heat low.

All of the transport studies in this region, however, have been based on observed synoptic wind data. The temporal and spatial resolution of such data is typically insufficient to evaluate the impact of mesoscale generated circulations (i.e., mountain/valley flows with typical horizontal scales of less than several hundred kilometers) on the large-scale transport. Therefore, in those studies, the transport modification of a pollutant mass by mesoscale circulations were not considered. Also in those studies, turbulence processes were not considered. Hence, while these synoptic transport evaluations provide bulk information concerning air movement over mesoscale domains, additional evaluations are required when thermally-induced circulations exist along the path of the pollution (see, for example, Pielke et al., ${ }^{8}$ for a detailed evaluation and discussion of this aspect).

The Lake Powell area, which is located in the Colorado River basin, is affected by valley-induced circulations. Our study is designed specifically to provide an evaluation of modifications to longrange transport by mesoscale effects in that area during the summer using the modeling tools outlined in the next section. Generally, the impact of mesoscale thermally-induced circulations on longrange transport of a polluted air mass is unaddressed in the literature. Therefore, although the present study provides a specific evaluation for the Lake Powell area, it also provides some insight as to the related impact of valley circulations in the general case.

\section{Modeling Aspects}

A numerical mesoscale meteorological model was applied in a two-dimensional domain along a northwestsoutheast cross section in the Lake Powell area (crossing through Page, Arizona; see Figure 1 for an illustration of the cross section location) as adopted in Yu and Pielke. ${ }^{2}$ In this region, the terrain acquires a general two-dimensional symmetry (i.e., uniform terrain along the lake direction), thereby justifying using a two-dimensional model version for the preliminary study reported in this paper. The model computed meteorological fields are used as input for a Lagrangian particles scheme to predict their transport/dispersion.

\section{Numerical Mesoscale Meteorological Modeling}

The formulation of the numerical mesoscale model used in the present study is given in detail in Pielke, ${ }^{9}$ Mahrer and Pielke, ${ }^{10}$ and McNider and Pielke, ${ }^{11}$ and also is summarized in Pielke. ${ }^{12}$ The model was validated successfully in studies of mountain/valley thermally-induced flows similar to the situation considered in the present study (e.g., Segal et al., ${ }^{13} \mathrm{McNider}$ and Pielke, ${ }^{14}$ Abbs, ${ }^{15}$ among others).

\footnotetext{
Copyright $1988-A P C A$
} 


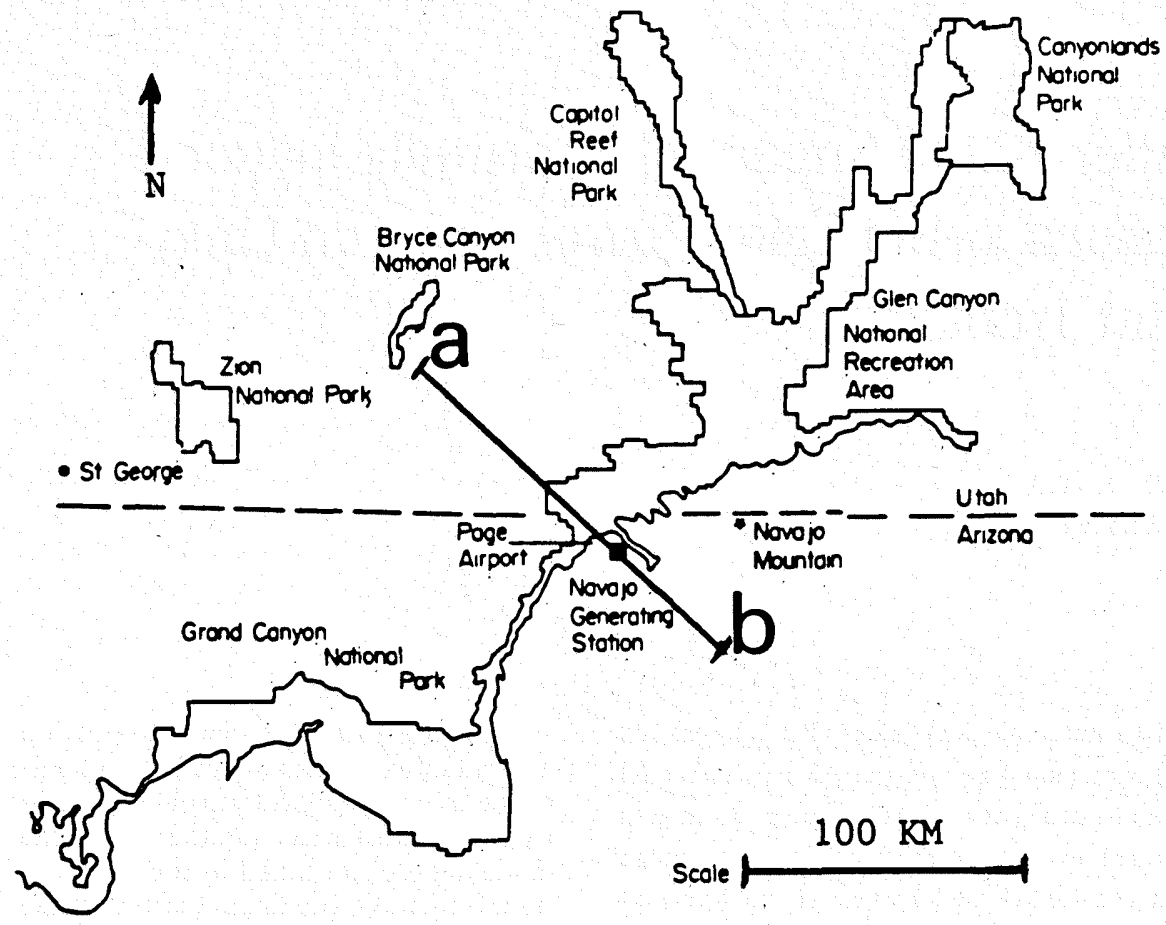

Flgure 1. Illustration of the Lake Powell area. The simulated cross-section is indicated by the line $a b$.

The terrain cross section used for the simulations, which consists of elevation variations larger than $1000 \mathrm{~m}$, is illustrated in Figure 2. The meteorological conditions simulated reflect July conditions in that area. Table I provides the general information related to the meteorological model simulations. Two background flow situations were simulated: 1) southeast synoptic flow of 2.5 $\mathrm{ms}^{-1}$ (i.e., crossing the valley perpendicularly) as a background flow; and 2) southwest synoptic flow of $2.5 \mathrm{~ms}^{-1}$ (i.e., along-valley direction).

\section{Transport/Dispersion Modeling}

Using the wind and turbulence fields computed by the meteorological model, a Lagrangian approach is applied to evaluate the transport and dispersion of pollutants. This dispersion and transport considers both the synoptic and mesoscale (i.e., valley circulation) flows. The detailed formulation is given in McNider ${ }^{16}$ and described also in Pielke et al., ${ }^{17}$ and McNider et al. ${ }^{18}$; thus, it is outlined in this paper only briefly. The model consists of tracking a release of a large number of particles representing a pollutant air mass advected and diffused, in the general case of a three-dimensional domain, using the formulation:

$$
\begin{aligned}
x_{i}(t+\delta t) & =x_{i}(t)+\left[u_{i}(t)+u_{i}^{\prime}(t)\right] \delta t \\
i & =1,2,3
\end{aligned}
$$

where $x_{i}(t)$ is the old $x, y$, and $z$ position of a particle and $x_{i}(t+\delta t)$ is its position following time interval $\delta t$ (in the present study $\delta t=20 \mathrm{sec}$ ); $u_{i}$ are the $u$, $v$, and $w$ velocities computed by the

Simulated domain top-9600 m

Domain horizontal extent- $150 \mathrm{~km}$

Model horizontal grid interval $-5 \mathrm{~km}$

Integration time step- $60 \mathrm{sec}$

Model vertical number of levels-28

Simulation start hour-2100 LST

Initial boundary layer depth-250 m

a) $0 \mathrm{~K} / 1000 \mathrm{~m}$ for $z \leq 250 \mathrm{~m}$

b) $2 \mathrm{~K} / 1000 \mathrm{~m}$ for $250<z \leq 2450 \mathrm{~m}$

c) $4 \mathrm{~K} / 1000 \mathrm{~m}$ for $2450<z \leq 9600 \mathrm{~m}$ Latitude $-37^{\circ}$ initial height was $600 \mathrm{~m}$ and its horizontal extent $15 \mathrm{~km}$. The volume was differentiated graphically into three layers indicated by $\alpha$ (bottom layer); $\beta$ (the medium layer); and $\gamma$ (the upper layer) as illustrated in Figure $4 a$. Transport simulations for this situation are listed in Table II (Cases 1-4). They consist of a release of the volume at various hours of the day with and without turbulent effects. This crossvalley simulation provides an illustration for situations involved with pollutant air transport to the Lake Powell area from New Mexico and Texas.

The second situation reflects a southwest synoptic flow of $2.5 \mathrm{~ms}^{-1}$ (i.e., along the valley direction). Particles were released in this case from the middle of the valley as illustrated in Figure 9a. The particles volume had an initial horizontal extent of $30 \mathrm{~km}$ and depth of $600 \mathrm{~m}$. The simulated transport cases for this situation are listed as Cases 5-7 in Table II. These cases provide an illustration for situations involved with pollutant air transport into the Lake Powell area from the direction of southern California.

The pollutant mass as represented by the particles was assumed in both simulations to be initially horizontally uniform in order to represent longrange transport into the region without mesoscale or turbulent dispersion upstream. This was done so that the influence of the mesoscale and turbulent flows in the Lake Powell area could be best visualized. In reality in both simulated cases, it is expected that intervening complex terrain between the source and the Lake Powell area would substantially influence the dispersion and transport in a similar manner as occurs within the Lake Powell area itself.

\section{Simulation Results}

\section{Cross-Valley Synoptic Flow- Meteorological Flelds}

Representative meteorological fields in the simulated cross section for the

Table I. Input parameters for the meteorological model.

Lowest terrain height within the simulated domain $-\sim 1300 \mathrm{~m}$ ASL

Solar declination for the simulated day-July 10

Initial potential temperature lapse rate $\partial \theta / \partial z$ : 

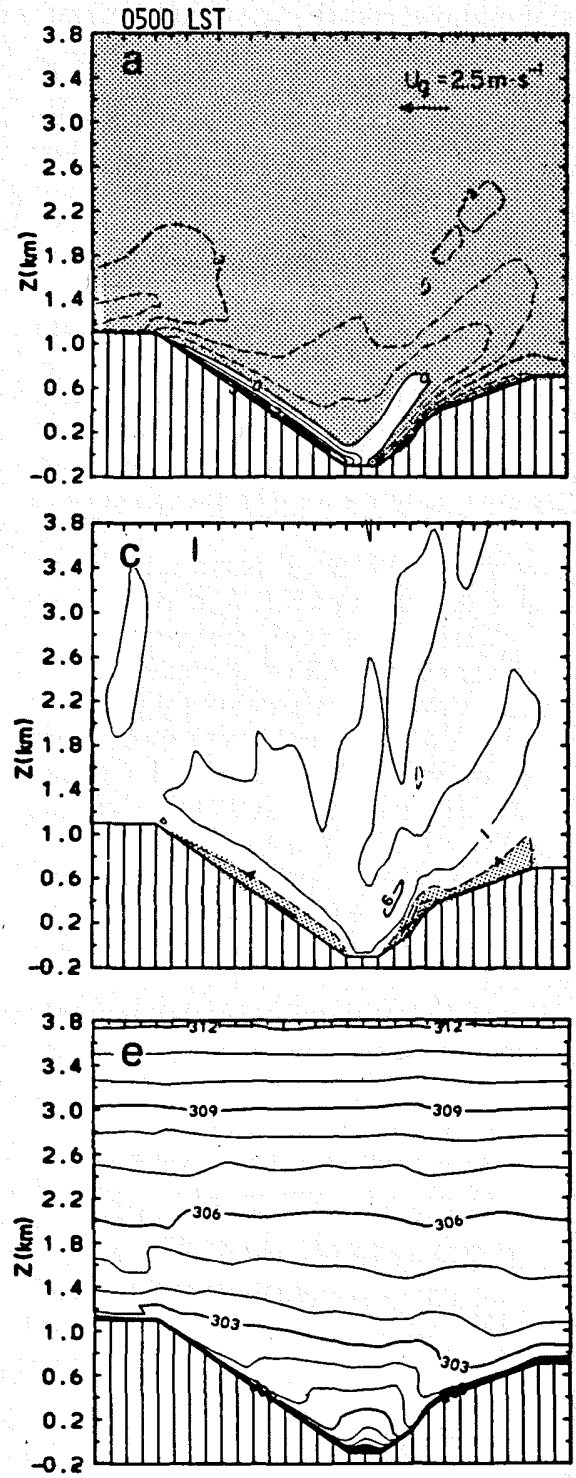
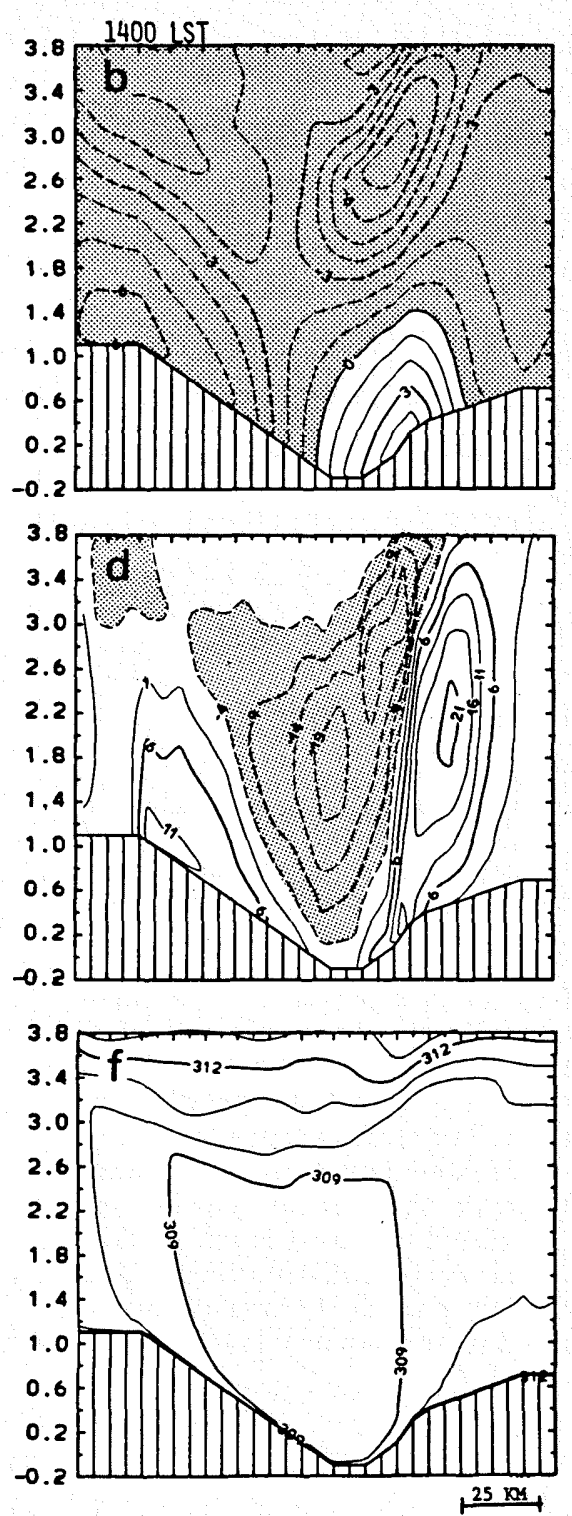

Figure 2. Representative meteorological fields for the cross-valley transport cases (southeasterly synoptic flow) for the simulated vertical cross section, for nighttime (0500 LST) and daytime (1400 LST); (a) and (b): $u$ component of the wind (cross-valley) is given in $\mathrm{ms}^{-1}$; dashed contours as well as shaded sections indicate negative values of $u$ (southeasterly flow); (c) and (d): vertical velocities $\left(\mathrm{cm} \mathrm{s}^{-1}\right.$ ); dashed contours as well as shaded sections indicate negative values of vertical velocities (subsidence); $(e)$ and (f): potential temperature $(\mathrm{K})$.

nighttime (0500 LST) and the daytime (at 1400 LST) are given in Figure 2. The geostrophic flow is southeasterly with a wind speed of $2.5 \mathrm{~ms}^{-1}$, as indicated in Figure 2a.

At the end of the nocturnal period, drainage flow is indicated to be shallow with speeds of several $\mathrm{ms}^{-1}$ (Figure 2a). The synoptic flow is perturbed only slightly at the valley top due to terrain dynamic effects and interaction with the valley thermally-induced circulation. A shallow layer with downward vertical velocities is modeled along the slopes as shown in Figure 2c (note that dashed contours as well as shaded sections in all the presented figures reflect negative vertical velocity values). The potential temperature field (Figure 2e) consists of a shallow, relatively cool surface-based inversion layer along the slopes which deepens toward the valley bottom where the turbulence is reduced.

The daytime meteorological features are presented for $1400 \mathrm{LST}$ when the thermally-induced valley circulation is around its peak. Upslope thermally-induced flows are somewhat less intense along the southeastern slope than those along the western slope (Figure 2b), which is attributed to a steeper western slope as well as the coupling of the upslope flows with an opposing synoptic flow along the southeastern slope. A significant feature in the flow field is the intensification of the flow aloft over the southeastern slope due to the return flow centered at about $3 \mathrm{~km}$ in Figure $2 \mathrm{~b}$ which was caused in response to the low level upslope flows (the flow intensification aloft to a peak wind speed of around $7 \mathrm{~ms}^{-1}$ is caused by a superposition of the return circulation and the southeast synoptic flow at that altitude). The horizontal convergence due to the coupling between the synoptic and thermally-forced flows along the southeastern slope is noticeable in the vertical velocity features (Figure 2d). Sinking of air over the middle of the valley involved with the upslope circulations is also pronounced. The potential temperature contours (Figure 2f) indicate the daytime depth of the boundary layer (mixing depth). An upward orientation of the contours is associated with the near-neutral thermal stratification which is typical for that layer. The boundary layer depth, as indicated by the temperature structure, is around $2-2.5 \mathrm{~km}$ for the presented hour. Finally, it is worth noting that the details of the near-ground wind and temperature structure are not evident in the figure because of the vertical resolution used in the plots.

\section{Cross-Valley Flow-Pollutant Transport}

Four illustrations of transport features are provided for this situation. Three releases in the morning hours and one in the evening, including a case in which turbulence effects were ignored, are shown.

Figure 3 provides the dispersion feature involved with a 0900 LST release (Case 1). The volume of the particles is located initially at the eastern boundary (see Figure 4a) of the domain with a depth of $600 \mathrm{~m}$ and a horizontal extent of three grid intervals $(15 \mathrm{~km})$. The vol-

Table II. List of transport case studies. $u$ indicates horizontal advection is included; $w$ indicates vertical advection is included; $T$ indicates turbulence is included.

\begin{tabular}{ccccc}
\hline Case & Release hour (LST) & Release location & Forcing & Figure No. \\
\hline & & Cross-valley transport & & \\
1 & 0900 & Southeast boundary & $u, w$ & 3 \\
2 & 0500 & Southeast boundary & $u, w, T$ & 4 \\
3 & 1100 & Southeast boundary & $u, w, T$ & 5 \\
4 & 2100 & Southeast boundary & $u, w, T$ & 6 \\
& & Along-valley transport & & \\
5 & 0500 & Middle of valley & $u, w$ & 8 \\
6 & 0500 & Middle of valley & $u, w, T$ & 9 \\
7 & 2100 & Middle of valley & $u, w, T$ & 10 \\
\hline
\end{tabular}



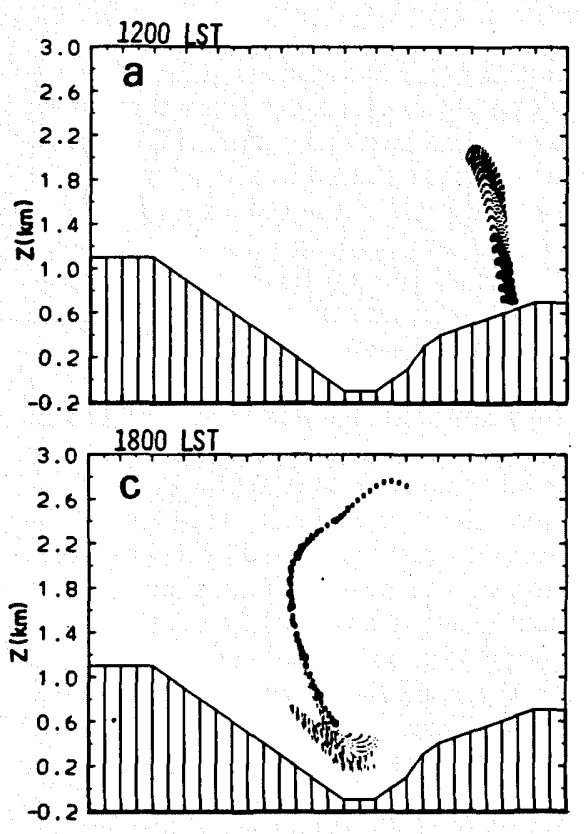

Figure 3. Features of pollutant particles dispersion at several selected hours for a release at 0900 LST. Southeasterly synoptic flow; only advection is considered (Case 1).

ume is differentiated graphically into three layers, enabling an evaluation of the mesoscale impact on each layer separately. The particles are advected by the $u$ (cross-valley wind component) and $w$ (wind vertical velocity) with the turbulent contributions ignored (i.e., $u^{\prime}=w^{\prime} \equiv 0$ ). The motivation for this simulation is the evaluation of the importance of the advection processes as compared to the turbulence processes in the studied cases. This objective can be accomplished by a comparison of the dispersion features presented for Case 1 with those obtained in the cases in which turbulence is considered. By 1200 LST the simulated pollutant mass is vented upward intensely in the convergence zone. By 1500 LST upward venting within the convergence zone is involved with the $\alpha$ layer particles, while the $\beta$ and $\gamma$ layer particles, which had been advected to the middle of the valley are sinking in the downward vertical velocities there. By 1800 LST the $\alpha$ layer particles also become trapped in the sinking motion, with the $\beta$ and $\gamma$ particles located at the low elevations of the valley as a result of the downward venting. Affected by the final stage of the daytime upslope circulation, the sinking particles were advected westward, while the $\beta$ and $\gamma$ particles were advected eastward and vented up the western edge of the convergence zone. As the nocturnal circulation is established following sunset, the particles effected by the reversal in the valley flow and their interaction with the synoptic flow, result toward the end of the night in the particle distribution shown for $0300 \mathrm{LST}$ in Figure 3d.

Case 2 is equivalent to Case 1 except
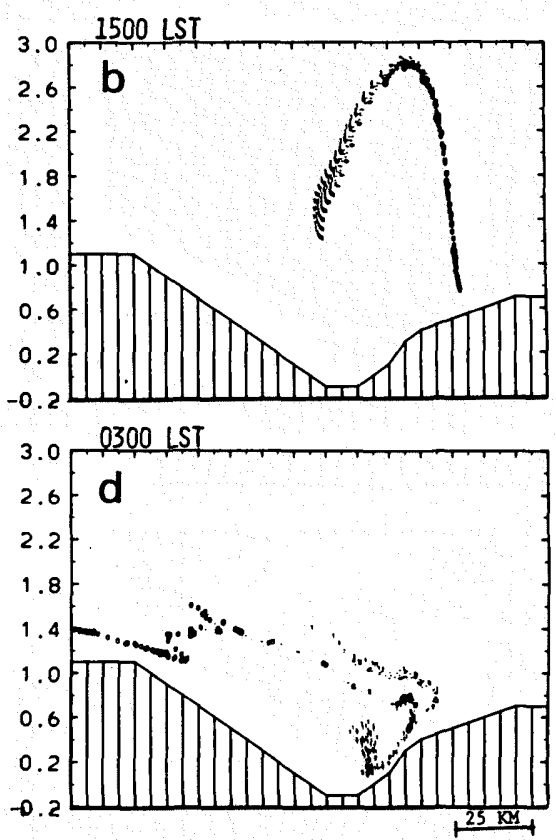

slopes; however, the southeastern portion is somewhat deeper as this region is affected by upward venting within the convergence zone. The synoptic flow over the shallow drainage flow during the night causes the pollutant mass to reduce its depth and to be advected gradually out of the domain as illustrated in Figure 4d.

Case 3 is the same as Case 2 except the release of the particles was at 1100 LST; thus, the impact of the daytime valley circulation in this case would appear immediately following the release. By 1400 (Figure 5a) the particles were advected somewhat in the downslope direction. The mass is noticeably affected by the upward and downward velocities at the slope convergence location and the mid-valley divergence zone following the patterns illustrated in Figure 3. It is worth pointing out that the sinking motion above the valley causes the particles aloft to be vented downward, otherwise, particles may not have been trapped within the valley. The dominance of the convergence/divergence effects leads by $1700 \mathrm{LST}$ to a division of the mass into two branches (Figure 5b). Similar nocturnal features shown in Case 2 are also obtained for this case, while the mass is advected gradually toward the northwest and out of the domain (Figure $5 c, d$ ).

Case 4 is the same as Cases 2 and 3; however, particles are released at 2100 LST (Figure 6). By 0600 LST the presented particle distribution had been established mostly due to horizontal
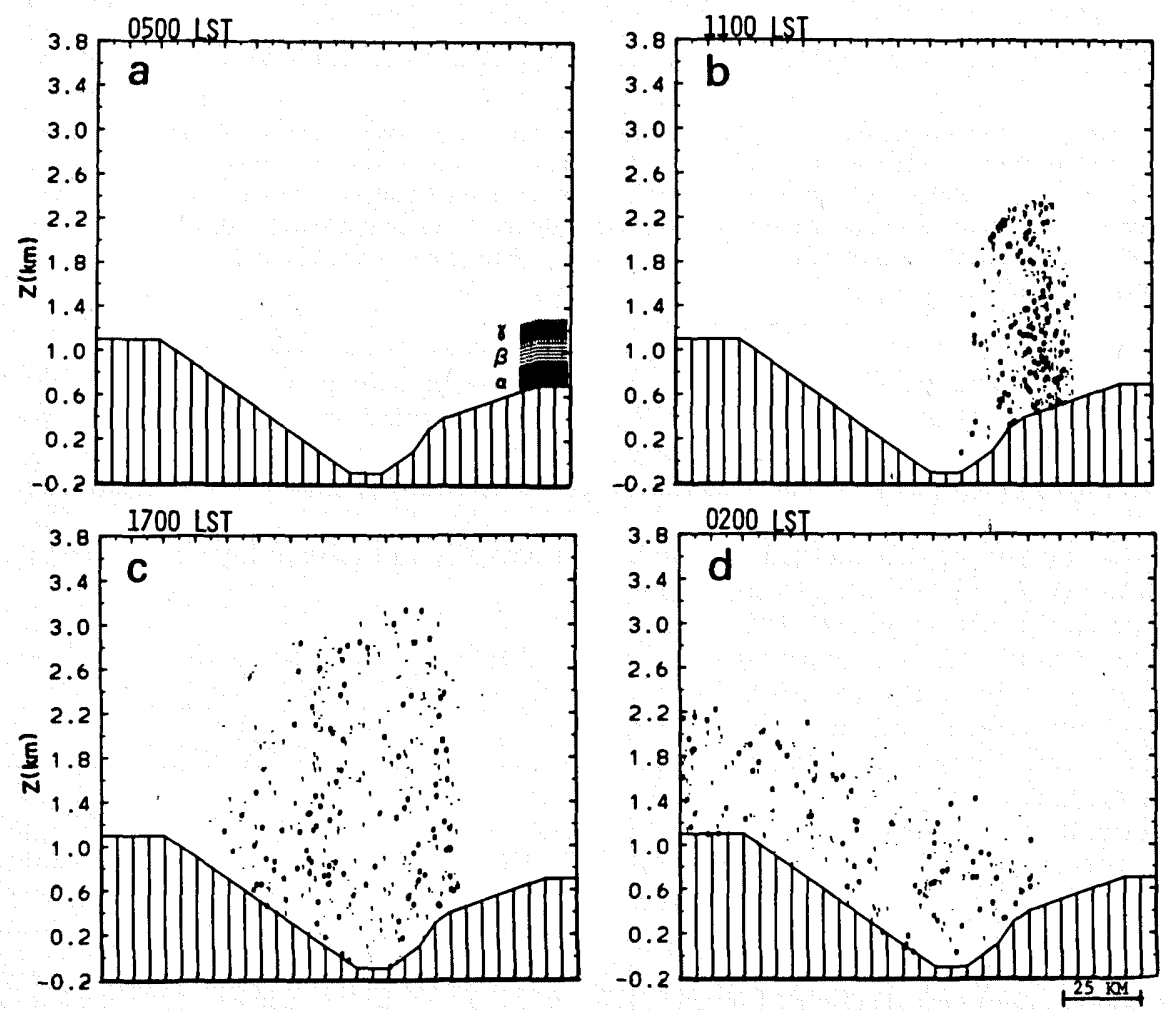

Figure 4. Features of pollutant particles dispersion at several selected hours for a release at 0500 LST. Southeasterly synoptic flow; advection and turbulence are considered (Case 2). 

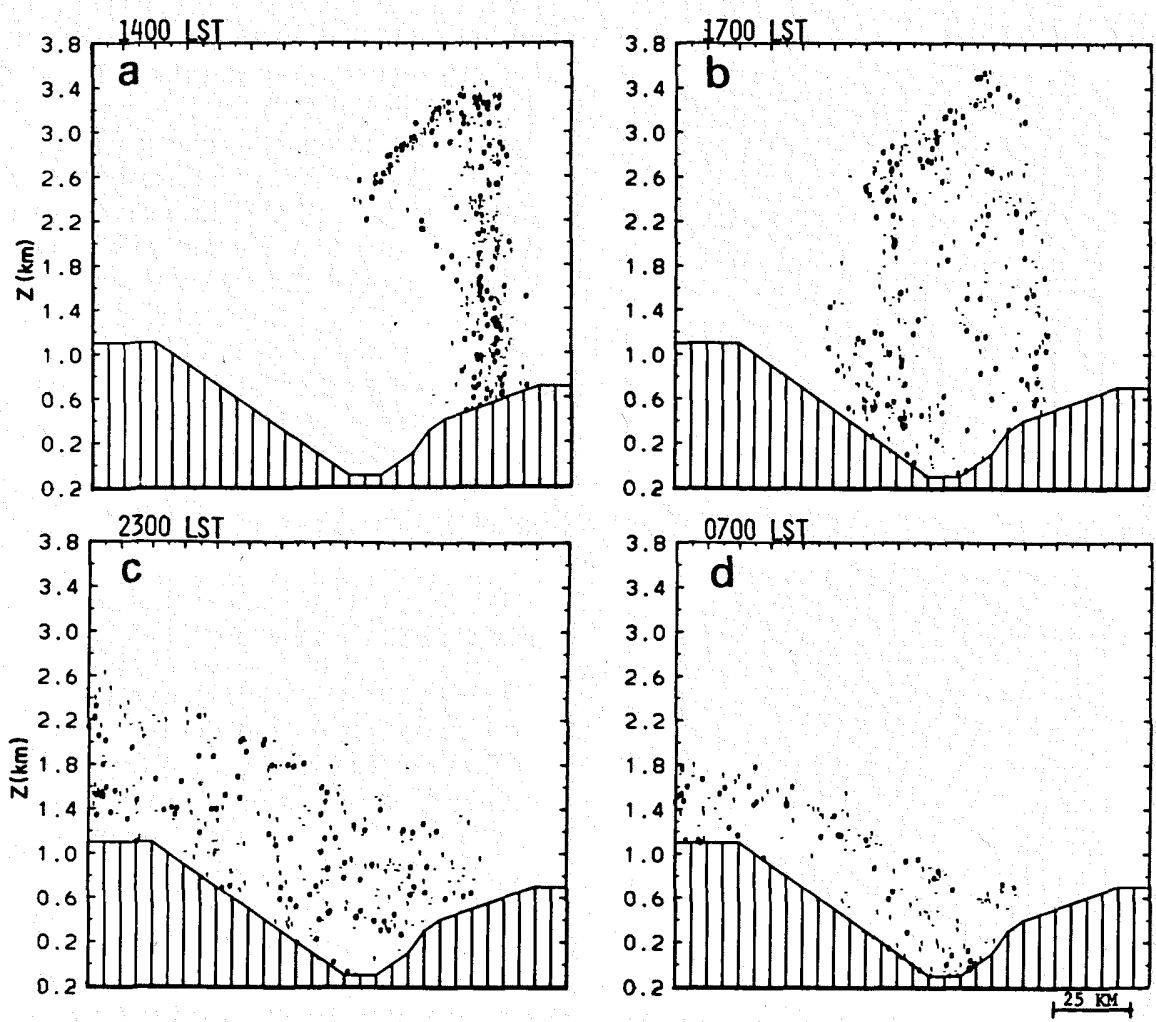

meteorological fields at night), are illustrated in Figure 7. Shallow drainage flow layers are evident from Figures $7 a, c$. Similar to the previous case study (i.e., the cross-valley simulation), a shallow nocturnal surface inversion also occurs (Figure 7e).

By 1400 LST a classical thermallyinduced circulation had developed along both slopes as evident by the $u$ component wind distribution (Figure 7b). The vertical velocity pattern (Figure 7d) illustrates the vertical branch of the mesoscale circulation. The characteristics of the potential temperature (Figure 7f) are similar to those reported for the cross-valley synoptic flow case study.

\section{Along-Valley Flow-Pollutant Transport}

In this situation a volume of particles is initially located in the lower elevation of the valley. It might reflect a portion of a larger volume covering the valley. Since the synoptic flow is southwesterly (i.e., along the valley), its impact on cross-valley transport is minor as pointed out previously. Therefore, only the development of cross-valley thermal flows, in addition to turbulence, are expected to cause an alteration in the spatial distribution of the particles in the cross-valley direction.

In the along-valley synoptic flow, the initial location of the pollutant mass is indicated in Figure 9a. Figure 8 presents the development involved with Case 5 where negligible vertical velocity is simulated with a $0500 \mathrm{LST}$ release. At 0800 LST the $\alpha$ and $\beta$ layers were most noticeably affected as the upslope flows began. By 1400 LST most of the $\alpha$ $\alpha$ and $\beta$ layers, which stil maintain a noticeable differentiation from the $\gamma$ layer particles. By 1200 LST vertical mixing affects all layers; however, the $\gamma$ particles, which during the earlier hours were advected faster, are at the front of the advected polluted mass, toward the northwest boundary. The $\alpha$ and $\beta$ particles being trapped in the valley are affected by thermallyinduced winds from both slopes at this hour. Significant advection of the pollutant mass during the next hours is evident by the pollutant distribution at 2100 LST. By that hour the $\gamma$ particles had been advected out of the domain, while some of the $\alpha$ and $\beta$ particles were still trapped in the valley.

\section{Along-Valley Flow-Meteorological Fleids}

A geostrophic wind of $2.5 \mathrm{~ms}^{-1}$ along the valley direction (i.e., southwest synoptic flow) is considered in this section. A small contribution of the synoptic flow to a cross-valley component occurred in the boundary layer (i.e., due to Ekman wind turning); however, the cross-slope wind component is primari-
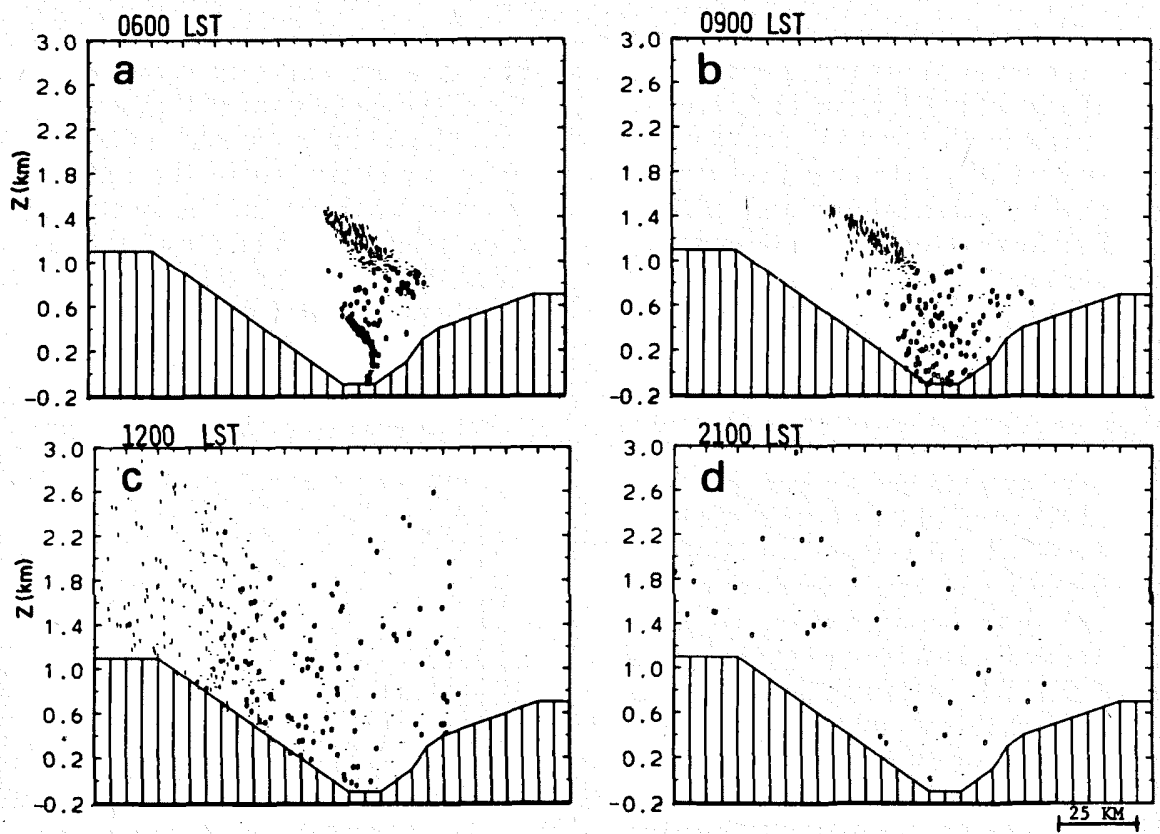

Figure 6. Features of pollutant particles dispersion at several selected hours for a release at 2100 LST. Southeasterly synoptic flow; advection and turbulence are considered (Case 4). 

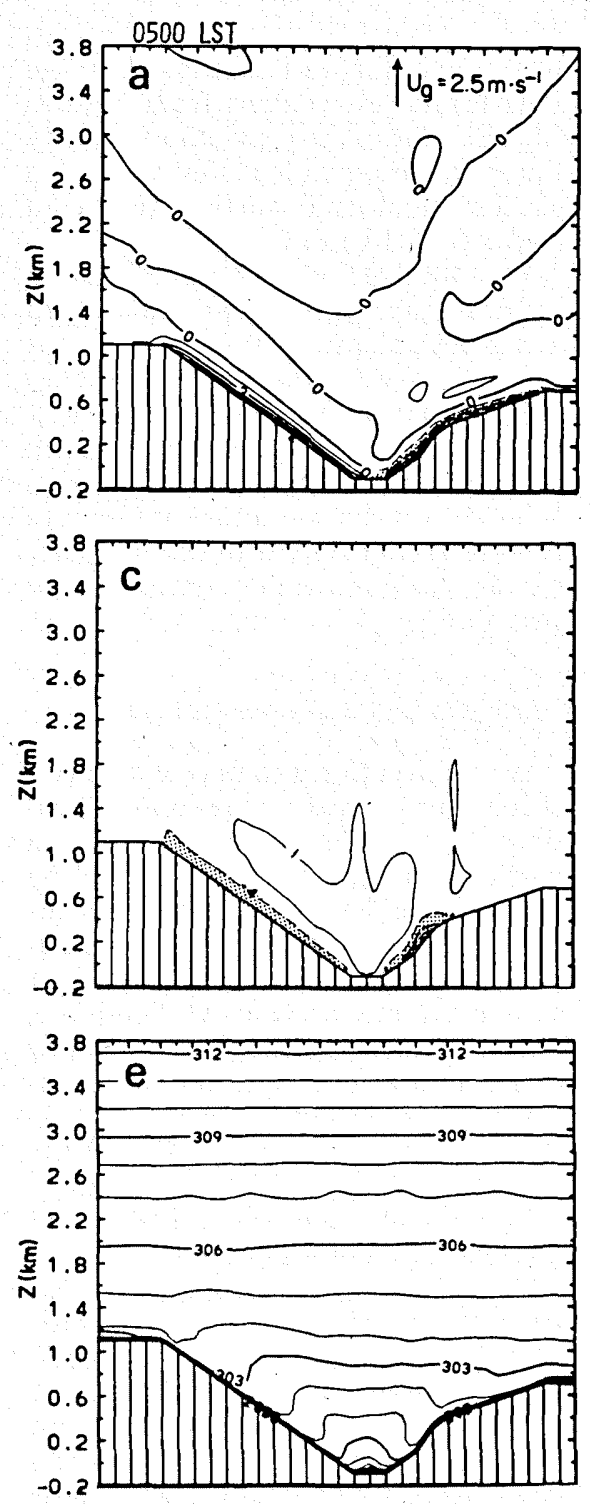
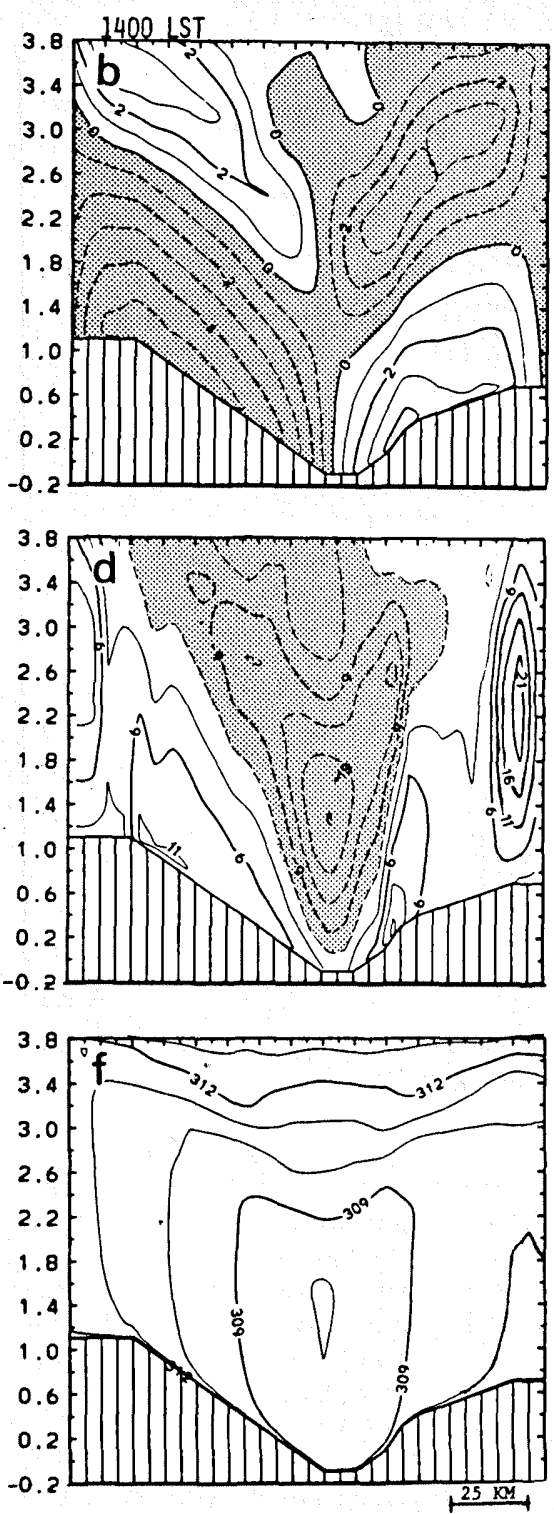

Figure 7. The same as Figure 1 except for the along-valley synoptic transport case (southwesterly synoptic flow).

particles were advected toward the boundaries of the domain, but were decelerating in the east, at the convergence zone. The $\alpha$ layer particles were affected by a less intense upslope and their advection toward the boundaries was slower.

Figure 9 presents a time sequence for Case 6 of the alteration of mass (initially released at 0500 LST) including diffusion by turbulence processes which should cause alterations in the basic features as obtained in the previous case. Following 9 hours from the release (Figure 9b), the development of upslope flows and a well mixed layer were evident by the generation of two separate and well mixed pollutant volumes along the slopes. The $\alpha, \beta$ and $\gamma$ layer particles were vertically well mixed up to an elevation of about $2.5 \mathrm{~km}$ above the valley bottom. Additional impact of the daytime upslope on the particle distribution was seen at $1700 \mathrm{LST}$. It consists of the generation of a relatively clear at- drainage flow was capped by a deep but light reversal flow aloft. This led to a mosphere at the valley bottom, as well as the advection of some of the particles out of the domain, mostly from the western boundary where the upslope flows were stronger. In the nocturnal period, relatively strong but shallow

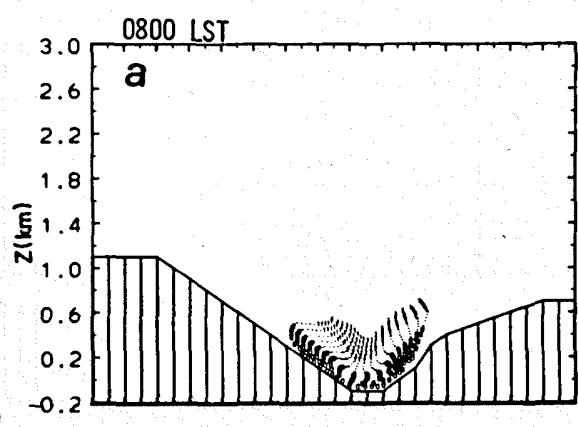

trapping of the pollutant mass over the valley 24 hours following the release (0500 LST second day).

For Case 7, where the release was at $2100 \mathrm{LST}$, the particular redistribution following 12 hours (0900 LST) is illustrated in Figure 10a. By that time the development of boundary layer vertical mixing and upslope flows were noticeable in the redistribution of the particles. Following an additional 12 hours (2100 LST), the vertically well mixed particles over the valley were similar to those obtained in Case 6 by that hour (Figure 9).

\section{Summary and Conclusions}

Two cases of the influence of mesoscale circulation on long range transport that are likely to be involved with the Lake Powell area during the summer were evaluated using a modeling tool. Pollutant mass was represented by particles which were differentiated graphically into three layers $(\alpha, \beta, \gamma)$ enabling a more detailed evaluation as to the transport features in each layer. The simulations provide insight as to the impact of valley thermal circulations and dynamic effects in that area on long-range transport. The results also illustrate expected influences on long-range transport of thermally- and dynamically-forced mesoscale flows associated with complex terrain in general. Additional work, of course, is needed to quantify the influence of such characteristics, such as the aspect ratio of the valley, synoptic flow intensity and atmospheric stability (or the Froude number) on the modification of synoptic long-range transport. Threedimensional simulations of the Lake Powell area, and other geographic regions which incorporate both mesoscale and synoptic influences, and turbulence effects are, of course, needed. Nonetheless, the two-dimensional simulations presented here demonstrate the expected major importance of mesoscale and turbulence effects on longrange transport across complex terrain.

The main conclusions of the present

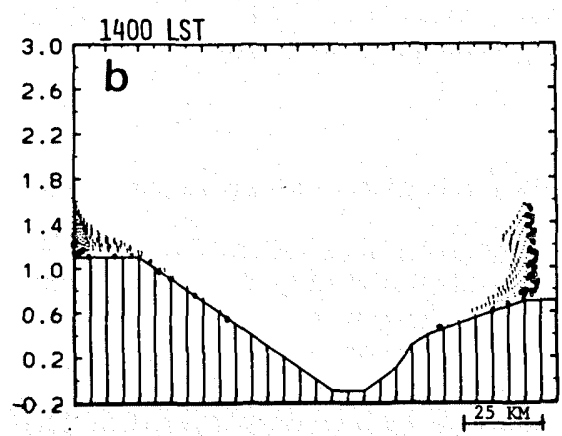

Figure 8. Features of pollutant particle dispersion at two selected hours for a release at 0500 LST. Southwesterly synoptic flow; only advection is considered (Case 5). 

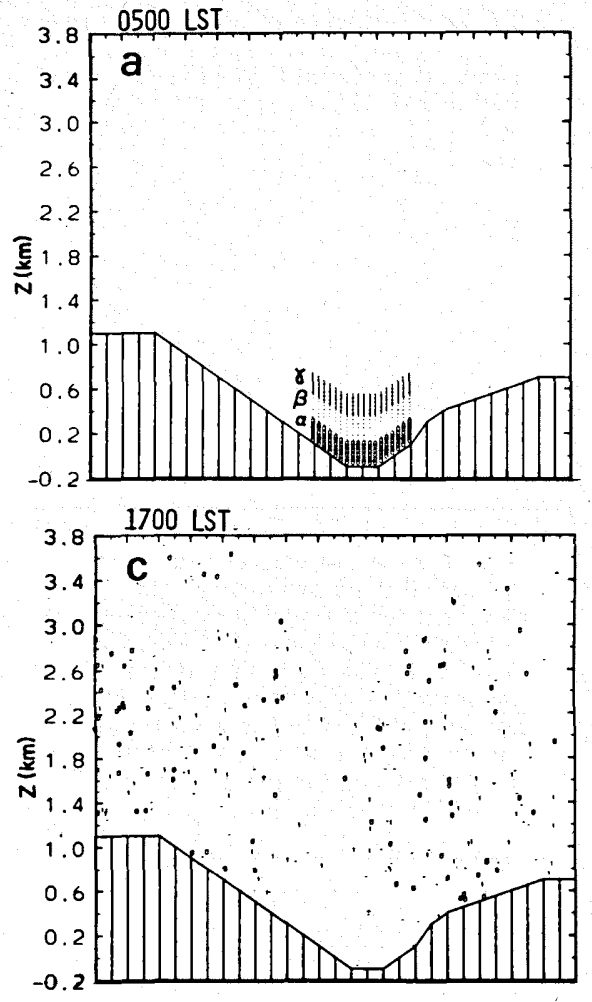

Figure 9. Features of pollutant particle dispersion at several selected hours for a release at 0500 LST. Southwesterly synoptic flow; advection and turbulence are considered (Case 6).

study relevant to long-range transport to the area are:

- Pollutants advected into the Lake Powell area by summer day southeast synoptic flow (i.e., a cross-valley large-scale wind) for the daytime releases were trapped for the simulated period $(\sim 24 \mathrm{~h})$ in the valley.

- Nighttime releases involved with cross-valley synoptic flow, although trapped in the valley, were transported out of the valley eventually (particularly the elevated polluted layers).

- Vertical and horizontal dilution of the pollution due to the induced thermal circulations distinguish it from the common and simple case of advection along flat terrain. Consequently, as outlined previously, acceleration and deceleration of their center of mass result. With a synoptic flow of $2.5 \mathrm{~ms}^{-1}$ and a domain of horizontal extent of $150 \mathrm{~km}$ as in the present study, with flat terrain and no mesoscale effects, the pollutants mass would have crossed the entire domain within about 16 hours. This rate of progress is faster than found for the various cross-valley wind cases (i.e., southeasterly wind transport).

- In the cases involved with pollutant mass transport within the valley along its orientation, the transport was affected by cross-valley ther-

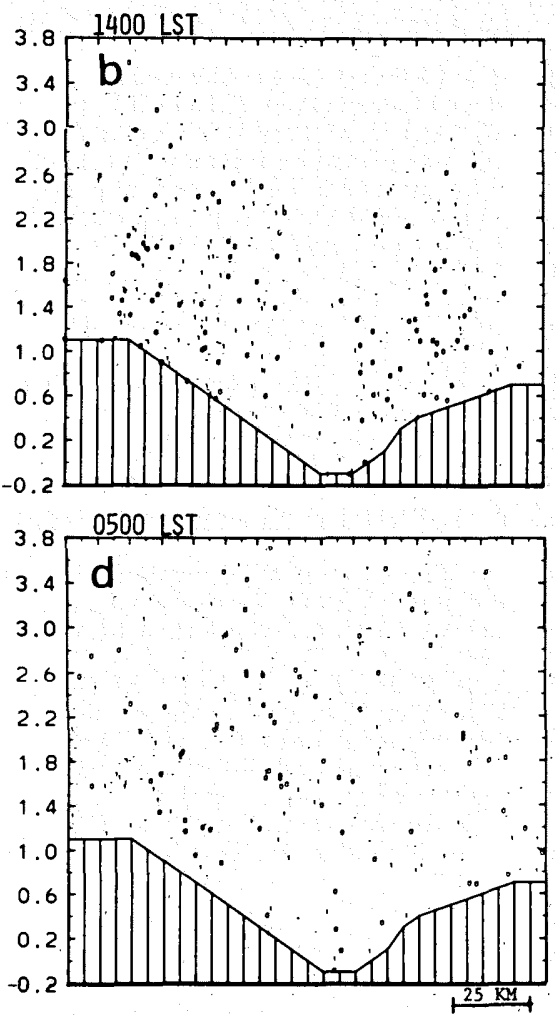

ing three-dimensional terrain considerations should lead to various distortions in the features obtained with the two-dimensional simulation. However, general conclusions of the transport/dispersion characteristics in this study should not be changed appreciably.

- Finally, based on the simulated cases, the study indicated the importance of vertical velocities involved with convergence/divergence zones on the vertical venting of pollutants, eventually causing significant alterations in the particle distribution from that which would occur without this venting mechanism.

\section{Acknowledgment}

This work was supported by the $\mathrm{Na}$ tional Park Service under contract NA81RAH0001, Amendment 17, Item 15 , and computer calculations were performed on the NCAR CRAY-1 Computer. NCAR is sponsored by the NSF. W. Malm, D. Henderson and R. Stocker are thanked for their valuable comments made during the completion of this work. The typing was ably handled by Sandra Wittler.

mally induced flows, in addition to the turbulence during the daytime hours. The results show that during the daylight hours there is a splitting of the mass into two branches along the slopes, in addition to a vertically well mixed layer. This resulted in a significant dilution of the particles over the domain; however, generally, the particles persisted over the valley area for at least 24 hours.

- The simulations were carried out under the assumption of two-dimensional symmetry of the terrain in the studied area (i.e., a uniform terrain along the valley direction), which is an idealization. Introduc-
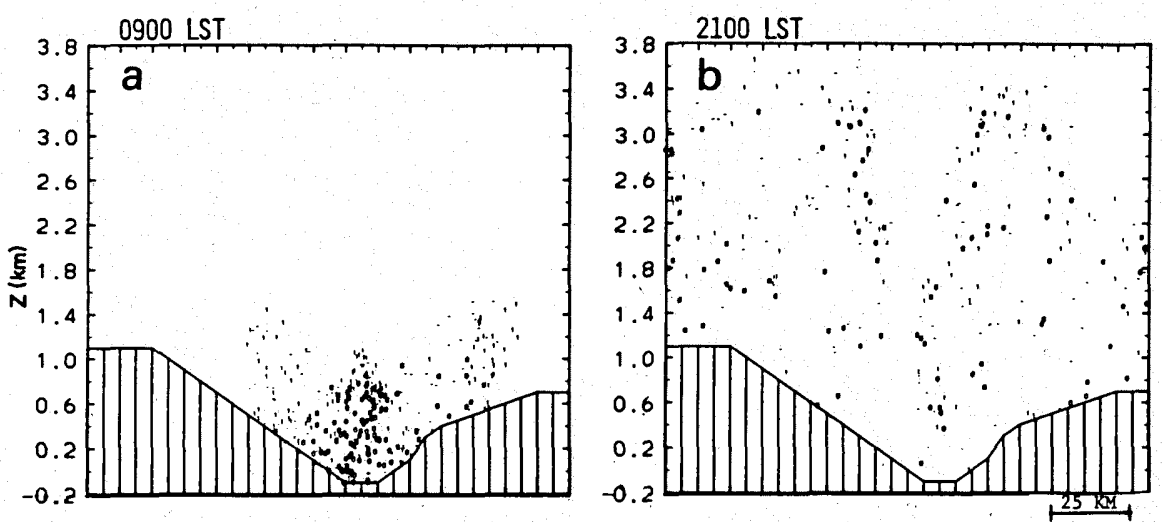

Figure 10. Features of pollutant particle dispersion at several selected hours for a release at 2100 LST. Southwesterly synoptic flow; advection and turbulence are considered (Case 7). 
5. E. S. Macias, J. O. Zwicker, W. H. White, "Regional haze case studies in the southwestern U.S.-II. Source contributions," Amos. Environ. 15: 1987 (1981).

6. R. G. Flucihini, T. A. Cahill, M. L. Pitchford, R. A. Eldred, P.J. Peeney, L. L. Ashbaugh, "Characterization of particles in the arid west," Atmos. Enviro. 15: 2017 (1981)

7. L. L. Ashbaugh, W. C. Malm, W. Z. Sadeh, "A residence time probability analysis of sulfur concentrations at Grand Canyon National Park," Atmos. Environ. 19: 1263 (1984).

8. R. A. Pielke, M. Segal, R. W. Arritt, M. Moran, "Mesoscale Influences on Long Range Pollutant Transport," presented at CIRA Workshop on Acid Deposition in Colorado, CIRA, Colorado State University, August 1986

9. R. A. Pielke, "A three dimensional numerical model of sea breezes over south Florida," Monthly Weather Rev. 102: 115 (1974).

10. Y. Mahrer, R. A. Pielke, "A numerical study of the air flow over irregular terrain," Contrib. Atmos. Phys. 50: 98 (1977).

11. R. T. McNider, R. A. Pielke, "Diurnal boundary layer development over slop- ing terrain," J. Atmos. Sci. 38: 2198 (1981).

12. R. A. Pielke, Mesoscale Meteorology Modeling, Academic Press, Orlando, FL, 1984.

13. M. Segal, Y. Mahrer, R. A. Pielke, "Application of a numerical mesoscale model for the evaluation of seasonal persistent regional climatological patterns," J. Appl. Meteorol. 21: 1754 (1982).

14. R. T. McNider, R. A. Pielke, "Numerical simulation of slope and mountain flows," J. Clim. Appl. Meteorol. 23: 1441 (1984).

15. D. J. Abbs, "Sea breeze interaction along concave coastline in southern Australia: Observation and numerical model study," Monthly Weather Rev. 114: 831 (1986).

16. R. T. McNider, "Investigation of the Impact of Topographic Circulations on the Transport and Dispersion of Air Pollutants," Ph.D. dissertation, University of Virginia, Charlottesville, VA 1981.

17. R. A. Pielke, R. T. McNider, M. Segal, Y. Mahrer, "The use of a mesoscale numerical model for evaluations of pollutants transport and diffusion in coastal regions and over irregular terrain," Bull. Am. Meteorol. Soc. 64: 243 (1983).

18. R. T. McNider, M. D. Moran, R. A.
Pielke, "Influence of diurnal and inertial boundary-layer oscillations on longrange dispersion," Atmos. Environ. (submitted 1987)
M. Segal is a research scientist and R. A. Pielke is a professor in the Department of Atmospheric Science, Colorado State University, Fort Collins, CO 80523. C.-H. Yu, deceased, was a graduate student at the same institution. This paper was submitted for peer review November 3 , 1986; the revised manuscript was received October 26, 1987. 